INVESTIGACIÓN/RESEARCH

\title{
LA ESPECTACULARIZACIÓN DEL DEBATE ELECTORAL: ESTUDIO DEL CASO EN ESTADOS UNIDOS
}

Graciela Padilla Castillo: Universidad Complutense de Madrid. España. gracielp@ucm.es

\section{RESUMEN:}

Un debate electoral ofrece un aspecto doble: confrontación intelectual y lucha por imponerse al adversario. Las recomendaciones sobre cómo debería ser un debate acentúan lo intelectual. Los medios de comunicación, sin embargo, presentan los debates como «¿Quién ganará?» o «¿Quién ha ganado?». Sin embargo, desde la comunicación política, resulta mucho más rico estudiar cómo se llegó a ello y cómo se preparó al debate, sobre todo si éste incluye elementos espectaculares y a veces, más propios de la ficción cinematográfica y televisiva. Para demostrarlo, se recuperan los tres debates electorales entre los candidatos George W. Bush y John Forbes Kerry, sucedidos hace justo una década, en 2004.

PALABRAS CLAVE: Comunicación política - Espectacularización - Campaña electoral - George W. Bush - John Kerry.

\section{THE ELECTORAL CAMPAIGN SPECTACLE: ELEMENTS AND CASE STUDY IN THE UNITED STATES}

\begin{abstract}
:
An election debate offers twofold: intellectual confrontation and struggle to impose the adversary. Recommendations on how should the debate be emphasize the intellectual part. The media have the discussions as 'Who will win?' or 'Who won?'.

1 Dra. Graciela Padilla Castillo: Profesora de la Facultad de Ciencias de la Información de la Universidad Complutense de Madrid, España. Doctora en Comunicación con Premio Extraordinario de Doctorado. Licenciada en Comunicación Audiovisual y Periodismo con Premio Fin de Carrera.
\end{abstract}

Correo: gracielp@ucm.es 
However, since political communication is much richer study how this came about and how the debate was prepared, especially if includes more typical of film and television fiction spectacular elements. To demonstrate it, we recover the three election debates between candidates George W. Bush and John Forbes Kerry, occurred just a decade ago, in 2004.

KEY WORDS: Political Communication - Spectacularisation - Election Campaign George W. Bush - John Kerry.

\section{INTRODUCCIÓN}

Un debate ofrece un aspecto doble: confrontación intelectual y lucha por imponerse al adversario. Las recomendaciones sobre cómo debería ser un debate acentúan lo intelectual. Los medios de comunicación, sin embargo, presentan los debates como “¿Quién ganará?” o “¿Quién ha ganado?”. Incluso, quienes participan en un debate, sobre todo si son políticos, aprovechan la víspera para anunciar su interés en que el debate sirva para esclarecer programas. No obstante, es frecuente que, inmediatamente después del debate, se den prisa en proclamarse vencedores.

Al final, ése es el quid del debate: quién resultó vencedor. Sin embargo, desde la comunicación política, resulta mucho más rico estudiar cómo se llegó a ello y cómo se preparó al debate. Al respecto, podemos recomendar un novedoso estudio de Valbuena y Padilla (2014: 271-302), los análisis de Valbuena (2010a y 2010b) y Padilla (2010), por separado, o los trabajos de Requeijo y Padilla (2011), García Lirios, Carreón, Hernández, Bautista y Méndez (2013), D’Elia (2013), o Piñeiro y Martínez (2013). Esas lecturas resultan de gran interés y recogen diversos y ricos marcos teóricos para quien desee ampliar retrospectivamente alguna de las vías analizadas.

\section{METODOLOGÍA}

El presente estudio recupera los tres debates presidenciales de los candidatos George W. Bush y John Forbes Kerry, sucedidos hace justo una década, en 2004, para analizar sus elementos de éxito y de fracaso, especialmente a partir de sus mecanismos espectaculares y espectacularizantes. Se demostrará que, más allá de los materiales clásicos para construir el argumentarlo del debate -materiales de credibilidad o de prueba personal, materiales de desarrollo y materiales de experiencia o dramáticos-, los candidatos recurrieron a elementos de producción, vestuario, maquillaje y puesta en escena más propios de la ficción de cine y de televisión.

\section{ANÁLISIS Y DISCUSIÓN}

\subsection{Antecedentes}

En 1960, setenta millones de ciudadanos norteamericanos presenciaron por televisión el primer debate electoral entre dos candidatos a ocupar la Casa Blanca. Los 
protagonistas eran Richard Nixon y John F. Kennedy, un joven que ganaría las elecciones, en gran parte, gracias a esta aparición televisiva y a cómo le presentaron los medios de comunicación.

Nixon era el presidente en cargo y apareció bastante ajado, aunque fortalecido por su buena gestión. Llegó a los estudios de la cadena CBS demasiado demacrado. Un accidente le había obligado a estar en reposo durante dos semanas en un hospital. Iba mal vestido y apenas tuvo tiempo suficiente para ser maquillado. Kennedy, en cambio, llevaba la teoría aprendida al pie de la letra. Estaba descansado y con un buen tono de piel, debido a unos días de campaña en California. Por si eso no era suficiente, iba perfectamente maquillado. A pesar de todo, no pudo ganar a su contrario en retórica. Así que los oyeron el debate por la radio, opinaron que Nixon era el ganador. Pero los estadounidenses que siguieron el debate por televisión, encontraron en el candidato más joven al que sería su nuevo presidente.

La conclusión no era, simplemente, que un joven candidato ganara a un experimentado presidente. Había nacido una nueva manera de hacer campaña política, una nueva forma de ganarse a la opinión pública. Dejaban de importar las palabras, las promesas electorales o los resultados económicos. Primaba la imagen, el vestuario, la presencia, el saber estar y comportarse ante las cámaras: el espectáculo mediático. Kennedy fue el primero en llegar a la Casa Blanca gracias a estas armas.

Lo que se va a analizar en las siguientes líneas, es cómo los candidatos George W. Bush y John Forbes Kerry intentaron utilizarlo de nuevo para ser presidentes de los Estados Unidos. El resultado es ya conocido. Lo desconocido es qué hubo detrás de sus palabras, sus mítines electorales en lugares muy bien seleccionados, sus vestimentas, o cómo influyeron esos tres debates, cara a cara, sobre el electorado y los indecisos: masa popular que puede hacer variar las elecciones hacia cualquiera de los dos bandos, hasta en el último voto escrutado. Es el claro triunfo de la opinión pública. Fueron los mismos ciudadanos los que decidieron. Sampedro (2000: 21) lo definió así: "Nos referimos a las opiniones y predisposiciones de la gente común. No son juicios de expertos o gobernantes, sino del pueblo y, por tanto, carecen del rigor de los primeros y de la responsabilidad de los segundos".

\subsection{Primer debate}

Tuvo lugar en la Universidad de Miami. Duró noventa minutos; tiempo suficiente para no resultar demasiado corto ni demasiado tedioso. Contó con una audiencia superior a los 70 millones de televidentes, el mismo número que en el debate Nixon Kennedy. Había sido ensayado desde hacía meses y ambas partes habían acordado que estaría limitado a cuestiones internacionales y de seguridad. Por ello, los temas más tratados serían la guerra de Irak, la de Afganistán y la seguridad nacional. Los candidatos no podían traspasar esos límites, lo que evitaría a Bush ser recriminado por una de sus asignaturas pendientes: la economía. Los datos mostraban que la familia media estadounidense vivía peor que hace tres años y medio y que "45 millones de estadounidenses no tenían seguro médico” (El Mundo, 8-10-2004: 15). 
Kerry tendría que guardarse esos datos sobre la mesa y atacar con otros argumentos. Era su primera opción. Comenzaba el primer asalto y los contrincantes se acercarían o alejarían de la Casa Blanca, según fuera su actuación estelar o desastrosa.

George W. Bush, como el entonces presidente en el final de su primera legislatura, se mantuvo obsesionado por defender la seguridad del país. Atacó a Kerry por ser un veleta (en inglés, "wishy-washy"), aludiendo claramente a sus votos cambiantes en el Senado, y le dijo: “Un hombre como usted, que cambia de opinión tantas veces, no es de fiar". John F. Kerry, en el otro lado, contaba con un buen expediente y unas iniciales mágicas, JFK, como el anterior presidente Kennedy, asesinado trágicamente aunque recordado con cariño por toda la población norteamericana. Era John Forbes Kerry, el único aspirante capaz de quitarle a Bush la Casa Blanca. Al final, logró imponerse. Sus armas fueron ataques continuos y argumentos para descalificar la actuación política de Bush durante sus cuatro años de legislatura. Las encuestas instantáneas le proclamaron ganador del debate.

Los resultados parecían claros después de esos noventa minutos de debate. George W. Bush mostró su "limitada capacidad retórica". Jugaba con la ventaja de sus "calculados novillos en Florida" ( $A B C, 1-10-2004: 40)$, ya que había visitado a las víctimas de los últimos huracanes casi treinta veces, intentando ganar los votos de ese estado. Mientras, Kerry intentó aplastarle con su imagen, como ya había hecho Kennedy con Nixon años atrás. El demócrata se presentó con un llamativo bronceado que dio pie a multitud de comentarios y bromas. Sus ayudantes optaron por argumentar que era producto de realizar actividades deportivas al aire libre. Sin embargo, algunos medios de comunicación consultaron a especialistas para conocer el origen de ese moderno y atractivo moreno y afirmaron que podía deberse a "un maquillaje corporal aplicado con aerosol". Con ello, además del tinte para ocultar las canas y las inyecciones de Botox para disimular las arrugas faciales, Kerry se ganó poder ser definido como "un metrosexual en el armario" ( $A B C, 1-10-2004$ : 40). Definiciones y bromas aparte, su imagen le hizo ganar el primer debate, con mínima ventaja, pero venció al fin y al cabo.

\subsection{El debate de "los número dos"}

Otro clásico de campaña electoral es el debate entre posibles vicepresidentes, que suelen enfrentarse cara a cara, para medir sus fuerzas y sus capacidades. Esto puede hacer perder o ganar votos al respectivo candidato a presidente. Durante esta campaña, los dos "números dos" eran Dick Cheney y John Edwards y se enfrentaron pocos días después del primer debate.

Dick Cheney, republicano, era un hombre muy maduro, de experiencia amplia y demostrada, aunque de carácter introvertido. Los medios norteamericanos le habían apodado, en varias ocasiones, como "el presidente en la sombra", el hombre que ordenaba a Bush las decisiones que tenía que tomar. Para la opinión pública, era el peor valorado de los cuatro candidatos: presidentes y vicepresidentes.

John Edwards, en cambio, personificaba el sueño americano y era altamente valorado 
por los electores, quizá más por su elocuencia y simpatía, que por sus dotes como político. Era hijo de un obrero convertido en millonario y como senador, había sido siempre valorado de manera positiva. Incluso John McCain, entonces senador republicano, confesó que no pudo con Edwards en un debate en el Senado. Así que el candidato demócrata sólo tenía que servirse de su lenguaje y de su imagen para dar continuidad al acelerón que Kerry había tomado en el primer debate. Mientras, la misión de Cheney sería simplemente frenar ese avance, contando con la ventaja de su experiencia.

Todos estos aspectos mostraban que ambos posibles vicepresidentes alcanzaban puntos a favor a ese debate de los "números dos". Los problemas llegaron en el debate en sí. Edwards se vio "censurado" porque el debate se hizo con los dos candidatos sentados en sillas de una misma mesa. Esto le impidió, en parte, dar rienda suelta a su discurso corporal, ya que afirmaba que prefería hablar de pie. Por otra parte, la diferencia de edad le quitaba importancia y credibilidad, ya que los dos candidatos parecían padre e hijo reprochándose mutuamente.

No quedó claro quién fue el ganador porque mientras uno de ellos ganaba en palabra, el otro ganaba en imagen y en experiencia. Sí quedó clara y reforzada la imagen que el público tenía sobre ellos. Cheney era el prototipo de anciano, sabio y conocedor de la vida y sus peligros. Los analistas americanos le comparaban con el personaje de Yoda, de La Guerra de las Galaxias, debido a su fuerza como consejero espiritual que ya ha vivido todo en la vida. Sin embargo, "para sus críticos (...) se parece más que nada a Darth Vader, el enmascarado personaje de coraza negra que milita en el lado más oscuro" (ABC, 6-10-2004: 28).

Por otro lado, Edwards, era definido como un gran "rainmaker", palabra que se refiere a aquellos hombres que consiguen grandes éxitos en el mundo de los negocios y de la política. Antes de llegar al Senado, ya era un conocido abogado, ganador de importantes y millonarios litigios en los que siempre convencía a los jurados populares. Algunos medios de comunicación estadounidenses llegaron a definirle como "una especie de segunda edición abreviada de Bill Clinton, ampliamente corregida en el capítulo de las tentaciones carnales" (ABC, 6-10-2004: 28). Estas características hicieron temblar a los ayudantes del presidente Bush, que vieron en él un peligro mayor que en Kerry. Le definieron como mercurial, metódico y un "zorro bajo el disfraz de Bambi" (El Mundo, 8-10-2004: 25).

La batalla no terminó en ese debate. Durante los días posteriores a ese encuentro televisado, Edwards y Cheney se enzarzaron en una "batalla dialéctica", debido a que Cheney había declarado que era la primera vez que veía a Edwards. Con estas declaraciones, intentaba hacer creer que el posible futuro vicepresidente escapaba, en numerosas ocasiones, de sus obligaciones políticas por no acudir al Senado. Esto indignó a Edwards, que acabó demostrando lo contrario y citó un encuentro y una conversación que habían mantenido en Washington, en el año 2001, durante la celebración del Desayuno Nacional de la Plegaria. Consiguió dejar a Cheney en evidencia y ganar un asalto que parecía perdido. Lo anecdótico de esta situación es 
que el debate se trasladó a las esposas de ambos candidatos: Elizabeth Edwards y Lynne Cheney, que siguieron debatiendo para dar la razón a sus respectivos maridos. Finalmente, el demócrata Edwards volvió a vencer, ya que una página Web (factcheck.org) corroboraba y ratificaba sus palabras.

Esta anécdota sirve, asimismo, para recordar que éste no fue el único enfrentamiento entre mujeres que se produjo durante la campaña electoral. Teresa Heinz Kerry y Laura Bush también cruzaron sus palabras, haciendo crecer la tensión y el espectáculo. Desde el principio, la esposa de Kerry había sido la "mujer rara". De hecho, ella se había definido así públicamente. Su imagen resultaba agradable por su lado caritativo, pero peligrosa por su "aspecto de millonaria consentida" (El Mundo, 22-10-2004: 34). Para terminar de echar abajo su imagen, dijo a la mujer de Bush, en su primer encuentro, que no le gustaban las amas de casa.

Estas mismas palabras ya le habían costado un disgusto con Hillary Clinton, en 1992, pero Heinz prefería seguir su línea. Se le ocurrió decir, en el periódico USA Today, que no sabía si Laura Bush había tenido alguna vez un verdadero trabajo; aunque "aparte de que para la millonaria del Ketchup, que trabajó en los 60 para Naciones Unidas, pero lo dejó tras su matrimonio con el heredero del imperio Heinz, se podría decir lo mismo, la republicana trabajó como profesora y bibliotecaria durante diez años en Texas, hasta que se casó con George W." (El Mundo, 22-10-2004: 34).

Al final, la demócrata tuvo que disculparse oficialmente por haber olvidado la experiencia profesional de Laura, que definió como "una de las más importantes posibles: enseñar a niños" (El Mundo, 22-10-2004: 34). A pesar de las excusas, Heinz se había equivocado de nuevo. Además, había olvidado que en Estados Unidos, es peligroso meterse con las amas de casa, porque la mayoría de los ciudadanos prefieren siempre a una primera dama tradicional y casera, que no trabaje y se dedique sólo a obras de caridad.

\subsection{Segundo debate}

Estuvo precedido por unas importantes declaraciones de Bush en las que admitía que "los informes del espionaje sobre las armas de Sadam eran erróneos" ( $A B C, 10-10$ 2004: 30). Acabó reconociendo que no existían tales armas pero argumentaba que "Estados Unidos está hoy más seguro con Sadam Husein en prisión" $(A B C, 10-10-$ 2004: 30) y que "buena parte de la información cosechada por nuestro espionaje era errónea y debemos averiguar por qué" ( $A B C, 10-10-2004: 30)$.

Estas declaraciones fueron detonantes para animar el segundo debate. Kerry ya tenía nuevos e importantes argumentos para desafiar a su competidor y dejarle en evidencia. Aseguró que el informe "es la prueba definitiva de por qué Bush no debería ser reelegido" (El País, 10-10-2004: 4) y se dirigió directamente a su contrincante diciendo: "Señor presidente, los estadounidenses merecen algo más que propaganda sobre esta guerra. Merecen conocer la realidad, no argumentos cuidadosamente preparados" (El País, 10-10-2004: 4). 
Este segundo encuentro tuvo lugar en San Luis, Misuri. Las cámaras querían reflejar si Bush renacería de sus cenizas después de haber sido vencido en Miami. John Kerry prefirió mantenerse prudente y se refugió con su equipo en Englewood, Colorado, mientras Bush comenzaba una campaña por email, en la que afirmaba que votar por Kerry era "votar por un mundo más peligroso" (El Mundo, 10-10-2004: 26). Ante estas acusaciones, el portavoz de Kerry se defendió afirmando que "no recuerdo que un presidente de EEUU tuviera nunca que desafiar a su rival de un modo tan bronco y negativo" (El Mundo, 10-10-2004: 26).

Después de nuevos cruces de acusaciones, por fin el segundo debate tuvo lugar. Era diferente al primero y más arriesgado en su formato, porque los candidatos podrían moverse libremente por el escenario, pero tendrían que contestar a veinte inquisitorias preguntas, hechas por el público y elegidas por el moderador. Ese público, formado por 140 personas, había sido elegido por una empresa de encuestas. Esta elección no era en absoluto gratuita porque cada uno de esos individuos seleccionados por Gallup se encontraba entre los definidos como "indecisos" y entregaron una pregunta para cada uno de los candidatos. Las respuestas tenían que ser rápidas. Bush y Kerry sólo disponían de dos minutos para contestar a cada una de ellas. Después, su oponente tendría 90 segundos para rebatirle. De hecho, las luces de tres colores puestas en el suelo marcaron estrictamente estos tiempos: verde (quedaban 30 segundos), amarillo (15 segundos), rojo (5 segundos) y rojo intermitente (tiempo agotado).

El sistema de debate y las encuestas anteriores hicieron que ambos candidatos tuvieran bastantes dificultades. Todos los sondeos hablaban de empate y para romperlo, tenían que ganarse en ese debate el favor de los indecisos. Kerry volvió a atacar a su contrincante. El demócrata le dijo a Bush que "el mundo es hoy un lugar menos seguro" (El Mundo, 2004: 28). Bush recurrió de nuevo a usar su argumento de que Kerry no tenía ideas claras y cambiaba de opinión constantemente, según la situación lo requiriera. Otra vez volvía a llamarle "veleta" o "wishy-washy" por sus cambios de opinión y recordó a toda la audiencia que Kerry había votado a favor de la Guerra de Irak en el Senado. La respuesta de Kerry fue: "Yo voté a favor de usar la autoridad necesaria por si Irak tenía armas de destrucción masiva" (El Mundo, 10-102004: 28) y como colofón, afirmó ante los periodistas que "Bush ve la vida de color rosa" (El País, 10-10-2004: 5).

A pesar de las contundentes declaraciones de ambas partes, no quedó claro quién fue el ganador de este debate. Se habló de "empate en el fondo, victoria de Kerry en la forma" (El Mundo, 10-10-2004: 26). Sin embargo, no quedó claro quién había defendido con más éxito sus argumentos. Sí se volvió a ver a un Bush nervioso al principio, que "arrancó destemplado y a voces, con la misma profusión de gestos que tan pésimo resultado le dio en el primer cuerpo a cuerpo. Pero luego entró en calor y pasó al ataque con mayor seguridad y golpes ocasionales de humor" (El Mundo, 1010-2004: 26). Mientras, Kerry se mantuvo siempre sereno y tranquilo, con gestos muy asertivos, mejor vocabulario y mayor dominio escénico. Como estuvieron igualados, se acabó diciendo que ganó Kerry por llevar el micrófono en la mano izquierda, 
mientras que Bush lo sujetaba con la derecha. Aunque es negativo reducirlo todo a un gesto, la población norteamericana lo acabó entendiendo así. Kerry volvía a ganar gracias a su imagen, a pesar de las duras palabras y acusaciones de Bush.

\subsection{Tercer debate}

Tenía todos los ingredientes para ser el más interesante y espectacular. Se produjo en el oeste, como si fuera un auténtico western: un duelo en Tempe, Arizona. Kerry prefirió concentrarse durante las horas previas en Santa Fe, Nuevo México, donde se relajó dando un largo paseo en bicicleta que daría la vuelta al mundo en forma de decenas de fotografías. Mientras, Bush repitió refugiándose en las afueras de Phoenix, antes de enfrentarse a su contrincante en el Casino Venetian.

La importancia de estos lugares no se debía sólo a las características curiosas, casi desérticas, de su paisaje. Arizona, Nuevo México y Nevada, con pocos habitantes pero de buen funcionamiento económico, eran un botín deseadísimo para ambos candidatos. Entre los tres estados sumaban 9 millones de habitantes y su fuerza electoral era pequeña: "aportan 20 votos a un colegio electoral en el que hacen falta al menos 270 para ser presidente" (El País, 15-10-2004: 8). Eran lugares donde más publicidad se lanzaba y más trabajaban los voluntarios para conseguir votos. Apenas se hacía campaña en estados como Nueva York o Tejas. Sin embargo, en el "corredor del cactus", ocurría lo contrario: la decisión sobre el voto nunca está decidida y los que quieren ser presidentes del país deben satisfacer a esos ciudadanos.

Ese término de "corredor del cactus" se refiere a un aspecto geográfico, ya que "comprende las cien millas que separan Tucson de Phoenix, aunque la denominación sirve para Arizona, Nevada y Nuevo México" (El País, 15-10-2004: 8). No hay que imaginarse esta zona como un gran desierto. Los datos económicos y demográficos sobre la zona siempre hablan de un gran y rápido crecimiento. Nevada, con un aumento del 82 por ciento superaba a Arizona, que tampoco se quedaba atrás con su incremento del 50 por ciento. Eran los estados norteamericanos que más habían crecido en los últimos catorce años. Estos crecimientos se debían a que la gente viajaba allí en busca de oportunidades, que dependían siempre de ese crecimiento. Acudían también nuevas empresas y el riesgo que asumían era siempre menor. De hecho, el paro en esos estados, era entonces de 4,4 puntos por debajo de la media nacional. Los dos candidatos conocían bien todos estos datos antes del tercer debate. Igualmente, sabían que los sondeos favorecían a Bush en Arizona y Nevada, y le empataban con Kerry en Nuevo México.

No se trataba sólo de pensar a nivel local, porque el resto del país volvería a estar muy atento para ver el nuevo encuentro. Los sondeos nacionales hablaban también de empate. La intención de Kerry era rematar el empate con su oponente y dejar abierta la carrera presidencial. Arizona era el lugar perfecto para pedir cuentas al presidente de todos sus errores. Bush, entre tanto, tenía que utilizar precisamente esa 
credibilidad, mostrando a Kerry como un candidato débil que no estaba, ni de lejos, preparado para gobernar el país. Ohio, otro de los "estados indecisos", también estaría muy pendiente. Era el estado que había "sufrido la mayor pérdida de empleos de todo EEUU en los últimos cuatro años" (El Mundo, 15-10-2004: 22) y republicanos y demócratas luchaban por cada voto de ese lugar marcado por la crisis industrial. A la lucha por el "corredor del cactus", se unía la lucha por el "cinturón del óxido". Había demasiados votos en juego y demasiada expectación.

El dudoso resultado, según la mayoría de los medios, era que Bush fue derrotado. Al parecer, Kerry saltó al escenario con más vitalidad y energía, dispuesto a defenderse con sus mejores armas. Bush sabía que Kerry le podía ganar con su imagen y atacó por el flanco de siempre, afirmando sobre el demócrata que "la retórica no está a la altura de su historial: ha sido senador 20 años y votó en 98 ocasiones a favor de subir los impuestos" (El País, 15-10-2004: 2).

Como defensa, Kerry reiteró su compromiso de anular las rebajas fiscales que favorecían a los más ricos y mantener los recortes de Bush para las clases medias. Para bordar estas promesas dijo, con contundencia, que "el presidente ha dado la espalda al bienestar de los estadounidenses" (El País, 15-10-2004: 2). Según los datos, tenía razón porque la economía del país no había mejorado durante el mandato de Bush. Pero el republicano recurrió a la religión, asunto donde, sin duda, se imponía a Kerry. De hecho, muchos medios afirmaban que Bush ganaría las elecciones gracias a su religiosidad, que le hizo ganar la confianza de esa amplia comunidad religiosa norteamericana. Bush dijo que la homosexualidad no era una opción para él y que "creo en la santidad del matrimonio, que es la unión entre un hombre y una mujer" (El País, 15-10-2004: 2). Por si no era suficiente, añadió más notas teatrales: "Soy católico y fui monaguillo" (El País, 15-10-2004: 2).

Defendieron posturas muy marcadas y claramente dirigidas a ganar votos de determinados votantes. Sin embargo, a partir de la lectura de los principales sondeos, Kerry saldría finalmente airoso y "resucitado", mientras que Bush naufragaba. No obstante, Bush sólo perdía el debate, no las elecciones, ya que los sondeos decían que seguía gustando más. Para los republicanos, "el presidente ha ganado por goleada y, al final, los estadounidenses verán un panorama en el que Bush les da confianza y les ofrece más seguridad y una economía que mejora" (El País, 15-10-2004: 3).

\section{GANAR A TRAVÉS DE LA PUESTA EN ESCENA}

Los seres humanos tendemos a retener en la memoria, con mayor facilidad, una imagen antes que una palabra. Con este axioma, los expertos en comunicación y marketing político intentan explotarlo al máximo. Bush, de hecho, mejoró su imagen, aunque no las opiniones sobre su intelecto, gracias a las imágenes que regaló a la opinión pública. Por ejemplo, aquel legendario aterrizaje en el portaaviones Abraham Lincoln costó más de un millón de dólares a los norteamericanos. Sin embargo, la imagen exhibió a un presidente heroico, casi divino, iluminado estratégicamente por los últimos rayos de sol, y acompañado por la pancarta que decía "Misión Cumplida". 
Nadie sabría diferenciar aquella imagen de una gran superproducción fílmica sobre héroes que salvan el mundo. Bush consiguió lo que buscaba. La puesta en escena fue maravillosa. Ni el director de cine de acción Jerry Bruckheimer hubiera conseguido algo parecido. Y lo cierto es que no le necesitaba, porque ya contaba con un amplio y profesional equipo para esta tarea. A la cabeza, tenía a su director de comunicación, Dan Barlett, que viajaba al lugar del mitin con varios días de antelación para seleccionar a los extras, al público, medir los encuadres de las cámaras y la cantidad de luz, "a ser posible crepuscular, que queda muy épico" (El País, 15-10-2004: 8).

Además de Barlett, destacaban: Grez Jenkins, ex productor de la Fox, Scott Sforza (director de escenografía) y Bob Deservi, ex cámara de la NBC y considerado el "gran mago de la iluminación". Fuera de la campaña y los debates, ese equipo buscó otra imagen para el presidente, más tranquila, menos heroica y tremendamente familiar y tradicional. El lugar elegido era el pueblo de Crawford, Texas, donde estaba el rancho de Bush. Allí, "las vacas pastan mansamente en los prados y las chicharras celebran el sopor permanente. En las calles desvencijadas reina el silencio unánime de 700 almas invisibles, con sus fusiles y sus rancheras. Estamos en la patria chica de George W. Bush, en los confines de la nada" (El Mundo, 24-10-2004: 26).

Ese panorama era el reflejo de la pura expectación ya que, en otro lado del pueblo, todos los ciudadanos esperaban con impaciencia la inauguración de la escultura alada Ángel de amor, realizada por la artista Lei Henneysey-Owen, en homenaje a Bush "por su servicio a la patria". Esta inauguración había sido anunciada previamente por la hoja parroquial, The McGregor Mirror, que hablaba del festejo en su portada. Asimismo, el cartel a la entrada del pueblo ya dejaba algunas pistas: "En él aparecen George y Laura Bush dándote la bienvenida y animándote a visitar la tienda de souvenir" (El Mundo, 24-10-2004: 26). Sólo faltaba que Bush saliera de su rancho para acudir a esa inauguración. De hecho, lo hizo: sentado en la parte posterior de su ranchera, con su perro Spot en brazos y saludando a sus vecinos.

Otro punto importante dentro de todas estas celebraciones, debates y similares, es el del vestuario. En el primer debate, fue visible que la tónica en la vestimenta de ambos candidatos era muy similar: "traje oscuro, camisa blanca, corbata poderosa y pins con la bandera americana" ( $A B C, 2-10-2004: 29)$. Los dos coincidieron en ese detalle; era una manera de mostrar su patriotismo. Les dio tan buen resultado que repitieron el mismo modelo en los dos debates siguientes y en cada uno de sus mítines.

Fuera de esas apariciones más serias, Bush y Kerry parecieron más modernos y optaban por los vaqueros. El republicano, como buen tejano, no podía aparecer sin su camisa de cuadros y sus jeans. Kerry optaba, en otras ocasiones, por disfrazarse: de ciclista, nadador o cazador. Debía meterse en todos los papeles posibles para que la mayor cantidad de ciudadanos se sintiera identificada en sus posibles presidentes.

Todo este espectáculo no podría hacerse realidad si no hubiera alguien que los organizase. Por eso, los candidatos también tenían a sus directores de campaña, 
hombres de confianza, encargados de controlar toda la parafernalia estética y escénica. Bush contaba con la ayuda de Karl Rove, conocido como "el copresidente". Se decía de él que siempre llevaba consigo una copia de El Príncipe de Maquiavelo y de El arte de la guerra, y que fue "el hombre que inventó a George W. Bush" (El Mundo, 13-10-2004: 22). Su mayor logro fue crear un documental en el que acusaba a Kerry de traicionar a los prisioneros de Vietnam, después de contactar con el grupo Lanchas Rápidas por la Verdad. El resultado fue titulado Honor robado: heridas que nunca sanarán y el Partido Demócrata reclamó a la Comisión Federal Electoral la retirada de la cinta antes de su emisión.

De Rove también se afirmaba que tenía el don de averiguar el curso político, antes de cualquier acontecimiento. Como profesor de la Universidad de Texas, explicaba a sus alumnos que las campañas negativas podían dar la vuelta a las campañas electorales. Además, antes de su trabajo con Bush, se le reconocía como un experto en tácticas de correo directo y anuncios negativos en radio y televisión. Saltó a la fama cuando hizo que Bush derribara a Anne Richards como gobernadora de Texas, en 1994.

En el lado contrario, Kerry fichó a Bob Shrum, el autor de sus discursos. Conocido en Estados Unidos como Srummy, nunca había ganado unas elecciones presidenciales con los candidatos de su país. Sí ayudó a Kerry a ganar su puesto de senador y sorprendentemente, tuvo éxito fuera, aconsejando a Tony Blair en Gran Bretaña, Andrés Pastrana en Colombia o Ehud Barak en Israel, lo que hacía de él un profesional de resultados dispares.

El espectáculo no se acababa en los debates. Kerry optó por una imagen que le beneficiara y siempre aparecían retratos suyos cuando más lo necesitaba. Antes del tercer debate, salió a montar en bicicleta y esa imagen fue publicada en cientos de periódicos. Consiguió parecer deportista y relajado, seguro de sí mismo y tranquilo como para salir a dar semejante paseo. Remarcando su carácter polifacético, hacia el 22 de octubre, fue a cazar ocas, con perro y toda la vestimenta adecuada, sonriente con rifle en mano. Era la imagen del norteamericano tradicional. Y aunque no había muchos norteamericanos cazadores de ocas, agradó mientras la televisión decía que la careta con el rostro de Bush era la más vendida para el próximo Halloween.

\section{EL PAPEL DE LOS MEDIOS DE COMUNICACIÓN DE MASAS}

Un aspecto importantísimo de estos debates es el papel que juegan los medios de comunicación, porque no todo es imagen y palabra. No basta con planear las apariciones de los candidatos. Después, viene otra tarea más importante, como es buscar la emisión y el apoyo de los medios. Ahí se produce una segunda campaña electoral, porque no se puede llegar al público si no es a través de los medios de comunicación de masas. En Estados Unidos lo saben muy bien desde la Guerra de Vietnam. Aquel largo y catastrófico conflicto les ayudó a entender el importante papel de los medios y aún hoy, se dice que el país norteamericano perdió, en parte, aquella guerra y el favor de sus ciudadanos, por la retransmisión diaria, y casi en directo, de todo aquello que ocurría en territorio asiático. 
En 1968, el corresponsal más famoso de Estados Unidos era Walter Cronkite. Este periodista mantuvo, hasta su muerte en 2009, su fama gracias a las millonarias audiencias de su programa televisivo. Su influencia, hace cincuenta años, era igual de importante que en el periodo electoral que tratamos. Acudió a Vietnam y definió objetivamente la guerra como sangrienta e insensata. El entonces presidente, Lyndon B. Jonhson, entendió que sus palabras serían seriamente tomadas en cuenta por la población norteamericana y pasó a la historia su frase de "Si hemos perdido a Cronkite, hemos perdido la guerra" (El País, 8-10-2004: 6).

El problema es que la televisión, según avanza la tecnología, ofrece mayor cantidad de noticias e imágenes y acaba saturando. Puede perder objetividad y el público deja de confiar en ella, especialmente en periodo electoral. La ciudadanía sabe que los medios están politizados y es difícil decidir a quién creer y a quién no. El resultado en Estados Unidos es que, "entre 1987 y 2004, la confianza del público disminuyó notablemente debido a que la objetividad de los medios disminuyó a su vez en un apabullante 30 por ciento" (El País, 8-10-2004: 6). Las grandes cadenas perdieron credibilidad y con ella, fieles espectadores y el público empezó a moverse hacia medios más pequeños, en lugar de hacia las grandes empresas informativas.

Esto hizo que programas como The Daily Show, de sátira informativa y poco reconocido antes de la campaña, se convirtieran en un éxito inesperado. Ese éxito mostraba la saturación del público y su poca confianza en lo que los medios llaman "información objetiva". En lugar de buscar información, inquirían la sátira, el humor, formas más sencillas, amenas y ligeras de enterarse de lo que ocurría. Durante el primer debate, el presentador del programa, Jon Stewart, llamó a sus enviados especiales para comentarlo. Estos se burlaron de Bush y de Kerry. El resultado fue seguido por miles de norteamericanos, especialmente jóvenes. La mayoría de los estudios afirmaba que los jóvenes de Estados Unidos, "no ven la CNN, ni los informativos de ninguna de las grandes cadenas. Saben lo que pasa en el mundo por el programa del canal cómico The Daily Show" (El País, 8-10-2004: 6).

Por otro lado, el humorista norteamericano Ali G utilizaba un programa de entrevistas para burlarse de políticos y famosos en Da Ali G Show. En prensa, el periódico satírico The Onion ( $L a$ Cebolla) crecía cada día en número de lectores y se expandía hacia nuevas ciudades.

Entre los grandes medios, el primero en definirse fue The New York Times que, tras el tercer debate, votó a favor de Kerry y criticó la gestión de Bush. Su titular del domingo 17 de octubre de 2004 era muy claro: "Kerry for President". No resultaba sorprendente si se tiene en cuenta que este diario siempre había apoyado a los candidatos demócratas para ocupar la Casa Blanca. Pero esta vez, llamaba la atención la claridad de su mensaje. Más adelante, ya dentro del texto, calificaban el mandato de Bush de "desastre", afirmando que "ha dejado el Gobierno en manos de radicales de derecha, así como de ideólogos e intereses industriales".

Times no se quedó sólo en generalidades y grandes frases. También habló de la 
política educativa del presidente, de Guantánamo, de los Derechos Humanos y de la Guerra de Irak. Fuera de estos ataques tan directos, que podían estar mejor o peor razonados, el diario criticó objetivamente la política económica del presidente republicano. Para apoyar el realismo de sus argumentos económicos, contaba con los resultados del índice Standard E Poor's 500 (S\&P). Este índice ya era uno de lo más seguidos en Wall Street, la Bolsa de Nueva York, y según sus resultados, las caídas durante los tres primeros años de mandato habían llegado a un 26,4 por ciento.

The Washington Post también siguió la estela del diario neoyorquino. El domingo 24 de octubre de 2004, publicó un curioso editorial con el mismo título: "Kerry for president". En él volvía a criticar a Bush duramente con frases como estas: "Nosotros apoyamos la guerra y creímos que el dictador iraquí suponía una amenaza que debíamos afrontar. Sin embargo, culpamos a Bush por haber exagerado ante la opinión pública los informes de Inteligencia y por alejarse de nuestros aliados de forma innecesaria; pero sobre todo, lo responsabilizamos por haber hecho caso omiso de consejos que habrían servido para preparar mejor la reconstrucción del país tras la guerra" o "Bush no se ha ganado un segundo mandato".

Aprovechando el tirón de estos editoriales y encuestas variadas, El Mundo, desde España y con fecha del 18 de octubre de 2004, publicó un cuadro sobre cómo había valorado Wall Street a sus presidentes y cómo había influido la Bolsa en que fueran, o no, reelegidos. Los resultados beneficiaron, sin duda, a Bill Clinton, demócrata, que "gozó de la confianza del parquet y, en su primer mandato, el S\&P subió un 15 por ciento" (El Mundo, 18-10-2004: 32).

No sería la única vez que el nombre del último presidente demócrata fuera mencionado durante la campaña. Kerry sabía que le necesitaba y acudió a él para buscar ayuda. Era el maestro del populismo, el verdadero imán del partido. Finalmente, el 25 de octubre, Clinton reapareció al lado del candidato demócrata. Los dos se dieron un verdadero baño de masas en Filadelfia (Pensilvania), ante 60.000 personas. El lugar era perfecto: Love Park (el Parque del Amor, en inglés). Allí, el ex presidente, a pesar de su reciente operación de corazón, se mostró feliz de estar con tanta gente. Estaba bastante más delgado que en su última aparición pública. Pero supo derrochar sonrisas y formular mensajes claros y eficaces a favor del cambio, en sus únicos cinco minutos de aparición.

Lejos de dar una imagen débil o enferma, se mostró radiante y vitalista y manifestó que "si esto no es bueno para mi corazón, no sé lo que será bueno". Reservó unas palabras a Bush y vaticinó que el republicano perdería las elecciones, como las había perdido su padre, doce años atrás. Según Clinton, "nuestros amigos del otro partido quieren un mundo en el que el poder y la riqueza se concentren en unos pocos. Nosotros queremos que se compartan las responsabilidades y actuar solos cuando no tengamos más remedio". Con todo ello, seguía restando credibilidad al republicano y pretendía recuperar el voto negro.

Por si Clinton no era suficiente, Kerry llamó a Al Gore, "el presidente que no pudo 
ser", vencido por Bush hacía ya cuatro años. Kerry, Gore y Clinton pretendían formar un "triunvirato demócrata" para los últimos días de campaña, mano a mano con George y Jeb Bush, en la lucha por los 27 votos electorales de Florida.

Sin embargo, todos los medios afirmaban que entre Kerry y Gore nunca había existido una buena química, especialmente desde que Gore apostara por Howard Dean en las primarias demócratas, en lugar de votar a Kerry. Por otro lado, Gore era "el raro" del Partido Demócrata y el único que se atrevió a criticar duramente a Bush por la Guerra de Irak cuando todos callaban. Se había convertido en el proscrito y le habían hecho desaparecer de la escena política. De hecho, Kerry temía que, en su regreso, su tono radical pudiera perjudicarle. Sin embargo, Gore no le defraudó y en la Universidad de Georgetown atacó a Bush por tener "una ideología rígida y de extrema derecha".

Mientras, Bush buscó un escudo para defenderse. Quizá, la palabra no era ya suficiente y decidió optar por el flanco publicitario, lanzando un spot inesperado y sorprendente. Era el anuncio de los lobos hambrientos. En él, una manada de lobos merodeaba nerviosa en un bosque frondoso, enseñaba los colmillos amenazantes y se movía hacia la cámara. Los lobos estaban preparándose para atacar Estados Unidos, o eso insinuaba el anuncio, si John Kerry era elegido presidente el 2 de noviembre. Por si la imagen no era suficientemente violenta, las palabras remarcaban el mensaje: "La debilidad atrae a aquellos que están esperando para hacer daño a América. En un mundo crecientemente peligroso, incluso después del primer ataque terrorista contra América, John Kerry y los progresistas en el Congreso votaron para recortar drásticamente el presupuesto de Inteligencia en 6.000 millones de dólares".

Todo este espectáculo había sido ideado por Karl Rove, artífice del anuncio, maestro en campañas difamadoras y consejero máximo del presidente Bush. Era el mismo que había ayudado a Bush a vencer al senador McCain, en las primarias republicanas del año 2000, difundiendo "rumores falsos que hablaban de que McCain tenía un hijo negro con una prostituta o que había traicionado a su país cuando estuvo cinco años como prisionero en Vietnam" (El Mundo, 18-10-2004: 32). Esta vez no había sido muy original. La idea del spot no era nueva, sino que imitaba a la utilizada por Ronald Reagan dos décadas atrás. En aquella ocasión, el protagonista había sido un oso, que representaba la amenaza soviética.

\section{OTROS LÍDERES MEDIÁTICOS}

Además de lo anterior, numerosos personas y personajes, conocidos por su propio nombre, influyeron, o intentaron influir, decisivamente sobre el electorado.

Michael Moore sorprendió con sus dos documentales, Bowling for Colombine y Fahrenheit 9/11. El primero consiguió el Oscar de la Academia a Mejor Documental y describía abiertamente, y sin secretos, el problema de las armas en Estados Unidos, accesibles para cualquier ciudadano estadounidense, incluso menores o adultos con problemas mentales. Por otro lado, Fahrenheit 9/11 intentó demostrar que no había 
armas de destrucción masiva en Irak y que una buena diplomacia hubiera evitado el conflicto. Por ello, se ganó el odio de multitud de políticos y senadores.

En octubre de 2004, en plena campaña electoral, se empezaba a hablar de otro film al que había que prestar atención: Team America: World Police. En ella, un grupo de marionetas, actuando a modo de comando de elite, ridiculizaban la guerra de Irak. Lo curioso es que llegaban imágenes y diálogos de la película mucho antes de su estreno en las salas. Sus creadores, también artífices de South Park, Trey Parker y Matt Stone, se sentían muy contentos debido a esta publicidad, aunque enojados porque la película había sido considerada violenta y no recomendada para menores de 17 años.

Tras Michael Moore y Team America, llegaría Kitty Kelley, autora de La Familia, biografía no autorizada de la saga Bush. La periodista confesó que empezó su libro el día en que George W. Bush ganó sus primeras elecciones presidenciales, ya que creía que era una victoria no merecida porque el candidato no poseía las aptitudes necesarias. Su campaña contra los Bush no fue tan abierta como la de Michael Moore, porque ella prefería la investigación, sin hacer demasiado. Por ello, sus críticas resultaban más demoledoras. De la lectura de libro, traducido y editado en España por Plaza y Janés, se deja entrever que la ascensión de Bush hijo fue fruto de toda una campaña económica de la familia, comenzada por su padre y cuyo objetivo, en última instancia, era colocar también como presidente a su hermano Jeb Bush, quizá en las siguientes elecciones: “No sé si lo conseguirá, pero Jeb es el miembro de la familia que siempre ha querido ser presidente. El actual presidente nunca habría anunciado su candidatura a gobernador de no haber sido porque su hermano lo hiciera también. Hay mucha competencia dentro de la familia" (La Razón, 9-10-2004: 22).

George Soros, conocido financiero internacional, también quiso alzar su voz en la campaña electoral. Este húngaro-estadounidense defendió a ultranza al candidato Kerry. Contaba con el dinero y con los medios necesarios para buscar votantes y los utilizó abiertamente a favor del candidato demócrata.

También se dio otro fenómeno que mostró que la mayoría de los artistas, músicos y actores norteamericanos estaban a favor del candidato Kerry. Sólo los actores Mel Gibson, Tom Selleck y Bo Derek dieron públicamente su apoyo a George W. Bush para que fuera reelegido. Mientras, un grupo de 540 artistas firmaron en Tejas un documento contra Bush, que sería publicado en The New York Times.

Otros nombres famosos querían aparecer fuera de ese manifiesto, aunque a favor de Kerry. Para ello, se creó la organización Rock the vote, con 1,4 millones de personas inscritas y el apoyo de personajes tan conocidos como Tom Cruise, Madonna o U2. Había que llegar a todo el público posible, incluidos los jóvenes, y los famosos podían ayudar a ello. Lo cierto es que los adolescentes estadounidenses nunca han destacado por acudir a las urnas en masa. Así, esta campaña intentó que esa apatía política disminuyera. Incluso el rapero Eminem, entonces con 32 años de edad, animó a los jóvenes argumentando que tenían que votar como él, que lo iba a hacer por primera vez en su vida. La razón, según el cantante, era evitar que Bush produjera 
más desastres. Lo dejó muy claro en su nuevo vídeo de animación, titulado Mosh.

\section{CONCLUSIONES}

Finalmente, George W. Bush ganó las elecciones presidenciales del 2 de noviembre de 2004. Contra el pronóstico de todos los sondeos y encuestas, se convertía en el presidente más votado de la historia de su país. Alrededor de 120 millones de estadounidenses acudieron a las urnas, elevando la participación al 60 por ciento y de ellos, 58,8 millones votaron al candidato republicano. Lograba así una legitimidad que no había conseguido en el año 2000 y se producía un verdadero récord histórico, ya que no se alcanzaban tales resultados desde hacía 35 años.

Por otra parte, durante el recuento, todos los ojos se pusieron en Florida y Ohio, estados que podían dar un vuelco a las elecciones hacia cualquiera de los dos bandos. Cientos de observadores internacionales de la OSCE (Organización para la Seguridad y Cooperación Europea), elegidos por la asociación Global Exchange, velaron por que no se produjeran irregularidades parecidas a las del año 2000. Y tras el recuento, estos profesionales calificaron las elecciones como "absolutamente limpias". Bush era el nuevo presidente y no se podía apelar contra ello.

El presidente republicano había esperado ansioso su reelección en el Centro Ronald Reagan de Washington. Mientras, Kerry se ocultó en un hotel de Boston, que curiosamente estaba en frente de otro hotel donde su abuelo se había suicidado tiempo atrás. Para los más supersticiosos, fue un error alojarse en ese lugar, ya que sólo podía augurar algo triste. Finalmente, lo más lastimoso fue su fiesta de derrota, organizada, inicialmente, para festejar una posible victoria sobre Bush.

George W. Bush fue reelegido presidente de los Estados Unidos sin ganar a su contrincante en la palabra, ni una sola vez, en los tres debates electorales. Sí ganó en el espectáculo, gracias a su optimismo y a sus apariciones icónicas, tan bien producidas desde lo artístico.

\section{BIBLIOGRAFÍA}

ABC, El Mundo, El País y La Razón.

D’Elia, N.S. (2013). “La mujer en la política: ¿igualdad o diferencia? Una invitación a la reflexión", Revista de Comunicación de la SEECI, Año XV (32), pp. 31-40.

García, C.; Carreón, J.; Hernández, J.; Bautista, M.; Méndez, A. (2013). “La cobertura de la prensa en torno a la inseguridad migratoria durante elecciones presidenciales", Revista de Comunicación de la SEECI, Año XVII (30), pp. 57-73.

Padilla Castillo, G. (2010). “Los conflictos entre Ética, Moral y Política en la Comunicación Institucional y Periodística de las series de televisión Sí, Ministro y Sí, Primer Ministro", CIC: Cuadernos de información y comunicación, nº 15, pp. 165-185. 
Comunicación política - Espectacularización - Campaña electoral - George W. Bush John Kerry.

Piñeiro-Otero, T. (2013). "Presencia, uso e influencia de los diputados del Parlamento de Galicia en Twitter", Revista de Comunicación de la SEECI, Año XV (32), pp. 106-126.

Requeijo, P. y Padilla, G. (2011). “Los discursos de Barack Obama: un ejemplo de espectacularización teledemocrática". En Berrocal Gonzalo, S.: Periodismo político: nuevos retos, nuevas prácticas: actas de las comunicaciones presentadas en el XVII Congreso Internacional de la SEP, 5 y 6 de mayo de 2011. Valladolid: Universidad de Valladolid, pp. 391-412.

Valbuena de la Fuente, F. (2010a). “Experiencia y cambio como asuntos recurrentes en los debates de los últimos cincuenta años en diversos países". En Martín Sánchez, I. y Martínez de las Heras, A. (Coordinadores): Historia y Comunicación en la España Contemporánea. Libro Homenaje a la Profesora María Dolores Sáiz. Madrid: Universidad Complutense de Madrid, pp. 495-516.

Valbuena de la Fuente, F. (2010b). "El humor en la comunicación política”, CIC: Cuadernos de Información y Comunicación, n $\mathrm{n}^{\mathrm{0}}$ 15, pp. 123-164.

Valbuena de la Fuente, F. y Padilla Castillo. G. (2014). “Los debates políticos televisados". En Herrero, J.C. (Ed.) y Römer, Max (Coord.): Comunicación en campañaDirección de campañas electorales y marketing político. Madrid: Pearson.

\section{Graciela Padilla Castillo}

Doctora en Ciencias de la Información por la Universidad Complutense de Madrid, con Premio Extraordinario de Doctorado, y Licenciada en Periodismo y Comunicación Audiovisual, con Premio Fin de Carrera. Ha completado su formación posdoctoral en la Universidad de California en Los Ángeles (UCLA) y ha sido profesora invitada en la Benemérita Universidad Autónoma de Puebla (México). Sus líneas de investigación se centran en Comunicación Política, Ética audiovisual, Ficción televisiva, Redes sociales y Estudios de Género. Es autora y coautora de medio centenar de capítulos de libro y artículos académicos, publicados en revistas de alto impacto (Revista Latina de Comunicación Social, Estudios sobre el Mensaje Periodístico, Historia y Comunicación Social, CIC Cuadernos de Información y Comunicación, Revista de Análisis Transaccional y Psicología Humanista, Icono 14 y Vivat Academia, entre otras). Asimismo, ha participado en más de una veintena de investigaciones con subvenciones competitivas, subvenciones privadas y proyectos de innovación docente. Es miembro activo del Instituto de Investigaciones Feministas (Universidad Complutense de Madrid) y colabora en la coordinación del Máster universitario en Comunicación Política y Empresarial (Universidad Camilo José Cela). 